\title{
Effects of dietary propionate on hepatic glucose production, whole-body glucose utilization, carbohydrate and lipid metabolism in normal rats
}

\author{
BY JOSETTE BOILLOT, CATHERINE ALAMOWITCH, \\ ANNE-MARIE BERGER, JING LUO, FRANÇOISE BRUZZO, \\ FRANCIS R. J. BORNET AND GERARD SLAMA* \\ Department of Diabetes, INSERM U 341 and Pierre \& Marie Curie University, \\ Hôtel-Dieu Hospital, 1 Place du Parvis de Notre Dame, 75004 Paris, France
}

(Received 20 October 1993 - Revised 28 February 1994-Accepted 12 April 1994)

\begin{abstract}
Increased intake of dietary fibres is associated with several beneficial effects on carbohydrate and lipid metabolism. The colonic fermentation of dietary fibres produces short-chain fatty acids (SCFA; acetate, propionate and butyrate). Some authors have suggested that SCFA could be partly responsible for the effects of dietary fibres. The purpose of the present study was to test the effects of one of the SCFA, propionate. The effects of moderate amounts of dietary propionate on insulin sensitivity and hepatic glucose production were studied in male Sprague-Dawley rats. Two groups of twenty-one adult rats were fed for 3 weeks on a diet containing $78 \mathrm{~g}$ propionate $/ \mathrm{kg}(\mathrm{P})$ or $78 \mathrm{~g} / \mathrm{kg}$ of a poorly fermentable cellulose (control group; C). Feed intake, body weight, fasting plasma glucose, insulin, free fatty acids, alanine, lactate, glycerol and $\beta$-hydroxybutyrate levels were measured weekly in anaesthetized rats. At the end of the feeding period basal hepatic glucose production (BHGP) was measured with a primed continuous infusion of $\left[3^{-3} \mathrm{H}\right] \mathrm{glucose}$ and the in vivo insulin sensitivity in rats was quantified by the euglycaemic-hyperinsulinaemic clamp technique (0.6 and $2 \mathrm{U} / \mathrm{kg}$ per h). At that time fasting plasma glucose measured in anaesthetized rats was significantly lower in group $P$ than in group $C: 7.7$ (SE 0.2) v. 8.5 (SE 0.2$) \mathrm{mmol} / \mathrm{l}$ respectively $(P<0.002)$; plasma insulin levels were not significantly different. Neither the BHGP (mg/min per kg; C 14.8 (SE 1.3), P 15.1 (SE 1.3); $n$ 7, not significant) nor the basal metabolic clearance (ml/min per $\mathrm{kg} ; 8.9$ (SE 0.8) v.9.9 (SE 1.1); not significant) were different between treatments. Hepatic glucose production and glucose utilization at the two insulin concentrations (approximately 500 and $1500 \mathrm{mU} / 1$ respectively, $n$ 7) did not differ significantly between the two groups. These results show that dietary propionate chronically ingested by normal rats could decrease fasting glycaemia, but from our findings, no effect on hepatic glucose production and whole-body glucose utilization could be clearly demonstrated.
\end{abstract}

Fatty acids: Glucose: Insulin: Liver: Propionate

In humans as well as in animals an increased intake of dietary fibre improves glucose tolerance (Jenkins et al. 1980; Anderson, 1986; Bornet, 1987; Vorster et al. 1988) and lowers cholesterol levels (Chen \& Anderson, 1986; Vorster et al. 1988). Different mechanisms have been proposed to explain these effects (Anderson \& Chen, 1979). Some authors have suggested that the short-chain fatty acids (SCFA), acetic, propionic and butyric acids, which are produced by colonic bacterial fermentation of undigestible carbohydrates (such as fructo-oligosaccharides, non-starch polysaccharides, pectins, gums), may be partly responsible for the effects of dietary fibres (Cummings, 1983; Venter \& Vorster, 1989; Wolever et al. 1989). The SCFA are rapidly absorbed from the lumen of the colon (Ruppin et al. 1980). The major SCFA is acetate which passes to peripheral tissues

\footnotetext{
* For reprints.
} 
to be metabolized by muscle (Skutches et al. 1979). Butyrate is largely utilized by the colonocytes (McNeil et al. 1978). Propionate is removed by the liver (Cummings et al. 1987). Thus, SCFA may influence the intermediary metabolism in the colonic epithelium, liver and peripheral tissues. More recent studies in man (Venter et al. 1990a) and in baboons (Papio ursinus; Venter et al. 1990b) have shown that diets supplemented with propionate and fibre decreased fasting plasma glucose, reduced area under the glucosetolerance curve and induced a decrease in the maximum insulin increment during this test. These results suggested that the improvement in glucose tolerance and insulin sensitivity observed with a fibre-supplemented diet may be mediated by the effects of propionate on carbohydrate metabolism. Our study was designed to examine the effects of dietary propionate on hepatic production and insulin sensitivity (taken as endpoint variables) measured by an isotopic method and clamp studies in the rat, which has been considered as a useful experimental model for the human fermentative breakdown of dietary fibre (Nyman et al. 1986).

\section{MATERIALS AND METHODS}

\section{Animals and diets}

Male Sprague-Dawley rats (Centre d'élevage R. Janvier, Le Genest-Saint-Isle, France) aged about $45 \mathrm{~d}$ and weighing $250 \mathrm{~g}$ were used. Approval for use of laboratory animals was given by the French Ministry of Agriculture. After a 1-week acclimation period they were housed at $22 \pm 2^{\circ}$ with a day-night cycle (light on from 07.00 to 19.00 hours) and kept in groups of three rats in polypropylene cages with a wire-mesh bottom to minimize coprophagy. They were allowed free access to water and fed ad lib. They were randomly allocated to either a standard (No. 210; UAR, Villemoisson/Orge, France) non-purified diet in which the usual cellulose source was replaced by a poorly fermentable paper cellulose (Keys et al. 1969;78 g/ $\mathrm{kg}$ ) or the same diet in which propionic acid, as $\mathrm{Na}$ and $\mathrm{Ca}$ salts, substituted for cellulose $(78 \mathrm{~g}$ propionate salts $/ \mathrm{kg}, 60 \mathrm{~g}$ propionic acid $/ \mathrm{kg}$, this quantity being equivalent to the amount of SCFA produced by colonic bacterial fermentation of $8 \mathrm{~g}$ dietary fibre (McNeil et al. 1978)). The energy available to the rats from the propionate supplement was assumed as $16 \cdot 3 \mathrm{~kJ} / \mathrm{g}$ according to Bär (1990) (heat of combustion for propionic acid $20.6 \mathrm{~kJ} / \mathrm{g}$ (Livesey \& Elia, 1988), energy conservation $80 \%$ ). For the type of poorly fermentable cellulose used we assumed that the available energy was negligible (Keys et al. 1969). Details of the composition of the diet are given in Table 1 . The diet supplied $59 \%$ of the total energy as carbohydrate, $24 \%$ as protein and $17 \%$ as fat.

\section{Experimental procedure}

In order to ensure a suitable number of animals at the end of the feeding period (week 4) with the glucose-clamp technique (i.e. $\geqslant$ fifteen animals per diet) we included thirty-three rats in each diet group at week 0 which was the basal prediet week; these sixty-six rats constituted the entire initial group as compared with the final subgroup of animals on which we report here. Also in order to ensure a suitable design for the experiment, six animals (three controls and three propionate-fed rats) of the same age entered the study (week 0 ) each week. The total of sixty-six rats were incorporated into the study of a period of 11 weeks. They were randomly assigned to one of the two diets. Each group of thirtythree rats received one of the two diets for 3 weeks. Feed intake was measured each week for $3 \mathrm{~d}$ consecutively and expressed as the mean for $3 \mathrm{~d}$ and three rats. Rats were weighed before the beginning of the feeding period and then weekly (W0, W1, W2 and W3 respectively). At $\mathrm{W} 0, \mathrm{~W} 2$ and $\mathrm{W} 3$, blood samplings were taken at 14.00 hours in rats fasting from 08.00 hours. Under these conditions it has been shown that gut-derived glucose is 
Table 1. Composition of the diets given for 3 weeks to normal sprague-Dawley rats

(In the control diet the usual cellulose content was replaced by $78 \mathrm{~g}$ poorly fermentable cellulose/kg and in the propionate diet, cellulose was replaced by $78 \mathrm{~g}$ propionate salts $/ \mathrm{kg}$ )

\begin{tabular}{|c|c|c|}
\hline Ingredients & Control diet $(\mathrm{g} / \mathrm{kg})$ & Propionate diet $(\mathrm{g} / \mathrm{kg})$ \\
\hline Casein & 225 & 225 \\
\hline Maize starch & 250 & 250 \\
\hline Sucrose & 300 & 300 \\
\hline Animal and vegetable fat* & 70 & 70 \\
\hline Cellulose & 78 & - \\
\hline Calcium propionate $\dagger$ & 一 & 46 \\
\hline Sodium propionatef & - & 32 \\
\hline $\mathrm{CaCO}_{3} \uparrow$ & $26 \cdot 7$ & - \\
\hline $\mathrm{NaCl} \ddagger$ & 9.7 & - \\
\hline $\mathrm{K}_{2} \mathrm{H}_{2} \mathrm{PO}_{4}$ & $24 \cdot 5$ & $24 \cdot 5$ \\
\hline $\mathrm{MgO}$ & 0.7 & 0.7 \\
\hline $\mathrm{MgSO}_{4}$ & 3.5 & $3 \cdot 5$ \\
\hline $\mathrm{FeSO}_{4} \cdot 7 \mathrm{H}_{2} \mathrm{O}$ & 0.3 & $0 \cdot 3$ \\
\hline $\mathrm{Fe}_{2} \mathrm{O}_{3}$ & 0.2 & 0.2 \\
\hline Trace elements & 0.7 & 0.7 \\
\hline Vitamin mix $\S$ & 10 & 10 \\
\hline
\end{tabular}

* Composition $(\mathrm{g} / \mathrm{kg}$ diet): saturated fatty acids 17 , monounsaturated fatty acids $31 \cdot 1$, polyunsaturated fatty acids 20.9; refined vegetable oils were used.

$\dagger$ The level of $\mathrm{Ca}(\mathrm{g} / \mathrm{kg}$ diet) $: 1.00$ control diet, 0.99 propionate diet.

The level of $\mathrm{Na}(\mathrm{g} / \mathrm{kg}$ diet $): 0.40$ control diet, 0.44 propionate diet.

$\S$ Supplied (mg/kg diet): retinol 6, cholecalciferol 0.0625 , thiamin 20, riboflavin 15 , pantothenic acid 70 , pyridoxine 10, myo-inositol 150, cyanocabalamin 0.05 , ascorbic acid 800 , tocopherols 170 , menadione 40 , nicotinamide 100 , choline 1360 , folic acid 5 , p-aminobenzoic acid 50 , biotin 0.3 .

negligible (Leturque et al. 1981). For this purpose, rats were lightly anaesthetized with diethyl ether, a $0.6 \mathrm{ml}$ blood sample was withdrawn from the retroorbital sinus and collected into heparinized tubes at $+4^{\circ}$, and $0.5 \mathrm{ml}$ were immediately deproteinized in the same volume of perchloric acid $(60 \mathrm{~g} / \mathrm{l})$. The supernatant fraction was neutralized and analysed for alanine (Williamson, 1974), lactate (Gutmann \& Wahlefeld, 1974), $\beta$ hydroxybutyrate (Williamson \& Mellanby, 1974) and glycerol (Wieland, 1974). The remaining blood $(0.1 \mathrm{ml})$ was centrifuged for immediate determination of plasma glucose with a glucose oxidase (EC 1.1.3.4) method (Beckman glucose analyser 2; Beckman Instruments, Fullerton, CA, USA). Plasma samples were stored at $-20^{\circ}$ until subsequent radioimmunoassay of plasma insulin and determinations of plasma free fatty acid (FFA) concentration.

\section{Surgery}

At the beginning of the 4th week, tests were performed at 14.00 hours in rats deprived of feed from 08.00 hours in twenty-one rats in the propionate group and eighteen rats in the control group, randomly selected from the initial group of animals. Rats were anaesthetized with sodium pentobarbital $(60 \mathrm{mg} / \mathrm{kg}$ body weight intraperitoneally; SANOFI, Libourne, France). Body temperature was maintained with heating lamps. One carotid artery was catheterized for blood sampling and a tracheotomy was systematically performed to avoid respiratory problems during anaesthesia. Infusions of insulin, unlabelled and labelled glucose were carried out using butterfly needles inserted into the saphenous veins. All these surgical procedures were followed by a $20 \mathrm{~min}$ stabilization period to allow glucose metabolism to return to a steady-state. 


\section{Euglycaemic-hyperinsulinaemic clamp studies}

The euglycaemic clamp was performed as described previously (Leturque et al. 1984; Pénicaud et al. 1985). Briefly, a $0 \cdot 15 \mathrm{ml}$ blood sample was collected before any infusion to determine basal plasma glucose and insulin levels. Then an exogenous insulin solution (Orgasuline, Organon, France) was infused at a constant rate of $0.02 \mathrm{ml} / \mathrm{min}$ through a saphenous vein. Blood glucose level was clamped at the basal level by a variable infusion of glucose solution ( $75 \mathrm{~g} / 1)$ with a Precidor pump (Infors, Basel, Switzerland). The exogenous glucose infusion was begun $1 \mathrm{~min}$ after the initiation of insulin infusion at a rate empirically set at $0.009 \mathrm{mmol} / \mathrm{min}$. The insulin dose-response values were obtained by infusing various amounts of insulin $(0.6$ and $2 \mathrm{U} / \mathrm{kg}$ per $\mathrm{h})$ to raise the plasma insulin levels to $500-1500 \mathrm{mU} / 1$. Blood samples $(30 \mu \mathrm{l})$ were collected from the carotid artery every $5 \mathrm{~min}$, and plasma glucose concentration was determined within $60 \mathrm{~s}$ with a glucose oxidase method. In each group the steady-state plasma insulin level and steady-state blood glucose level were reached 55-60 min after the beginning of insulin infusion. At 60, 65 and $70 \mathrm{~min}$ of clamp, blood samples $(0.2 \mathrm{ml})$ were withdrawn for determination of glycaemia, glucose specific activity (GSA) and steady-state plasma insulin levels.

\section{Endogenous glucose production}

Endogenous glucose production in the basal (fasting) state as well as during clamp studies was measured with the tracer-dilution method. A priming constant infusion of $\left[3-{ }^{3} \mathrm{H}\right] \mathrm{glucose}$ (Amersham, France), an irreversible tracer (Katz et al. 1974), was delivered by the saphenous needle. The $\left[3-{ }^{3} \mathrm{H}\right]$ glucose priming dose was $4 \mu \mathrm{Ci}$ followed by a continuous intravenous infusion at a rate of $0 \cdot 2 \mu \mathrm{Ci} / \mathrm{min}$. The steady-state of $\left[3-{ }^{3} \mathrm{H}\right] \mathrm{glucose}$ specific activity was reached in $60 \mathrm{~min}$ both in the basal-state studies and in the clamp studies. During the final $15 \mathrm{~min}$, three blood samples were withdrawn and analysed immediately with a glucose analyser. Another portion of the blood sample was used for the measurement of GSA, and remaining plasma was frozen at $-20^{\circ}$ for subsequent radioimmunoassay of plasma insulin concentration (see below).

\section{Analytical methods}

Glucose. Plasma glucose concentration was measured during clamp studies as described previously.

Insulin. All samples were assayed in the same batch using a rat standard (studies in the basal state and plasma withdrawn during the animal follow-up or a human standard (clamp studies; CIS International kits, Gif sur Yvette, France).

Free fatty acids. Plasma FFA were measured by an acyl-CoA oxidase technique (Wako Chemicals GmbH, Germany).

Glucose specific activity. GSA was determined using the Somogyi (1945) method. Blood samples $(0.05 \mathrm{ml})$ for determination of specific activity of the $\left[3-{ }^{3} \mathrm{H}\right]$ glucose were deproteinized with $0.25 \mathrm{ml}$ each of $0.15 \mathrm{M}-\mathrm{Ba}(\mathrm{OH})_{2}$ and $0.15 \mathrm{M}-\mathrm{ZnSO}_{4}$ and immediately centrifuged. A portion of the supernatant fraction was used for the determination of glucose concentration by a glucose oxidase method (Boehringer, Mannheim, Germany). Another portion of the supernatant fraction was evaporated to dryness at $70^{\circ}$ to remove ${ }^{3} \mathrm{H}_{2} \mathrm{O}$, the dry residue was redissolved in $0.2 \mathrm{ml}$ distilled water before addition of $3 \mathrm{ml}$ scintillation solution (Ready $\mathrm{Gel}^{\mathrm{TM}}$; Beckman Instruments) and counted in a scintillation spectrometer. GSA was calculated by dividing the $\left[3-{ }^{3} \mathrm{H}\right]$ glucose infusion rate (counts/min) by the steady-state value of glucose from the three samples withdrawn at the end of the experiments. Mean coefficient of variation of GSA in both groups was $9 \%$. The rate of glucose appearance ( $\mathrm{Ra}$ ) in the fasting state was calculated using Steele's (1959) 
equation. In the basal state the rate of endogenous glucose production is equal to Ra. In the clamp studies $\mathrm{Ra}$ was equal to the rate of glucose disappearance (Rd), the rate of endogenous glucose production was calculated by subtracting the exogenous steady-state glucose infusion rate from $\mathrm{Ra}$. The whole-body glucose utilization rate (GUR) is equal to Rd. Blood samples were withdrawn at 60,65 and 70 min after the beginning of the infusion of the labelled glucose and analysed as described previously.

\section{Statistics}

Results are expressed as means with their standard errors. The computer program StatView $\mathrm{SE}+$ Graphics TM for a Macintosh computer was used for statistical analysis. Comparisons for a given variable during clamp and from week-to-week between the two groups were performed using Student's $t$ test for unpaired data.

\section{RESULTS}

\section{Effects of diet on feed intake and body weight}

Table 2 summarizes results of feed intake and body weight in the two subgroups of animals. The energy density was 16.3 and $15.5 \mathrm{~kJ} / \mathrm{g}$ for propionate and control diets respectively. After 1 week of feeding, rats consumed smaller amounts of diet containing the propionate than the control diet; presumably, this was due to the palatability of the diet. Once this initial period of adaptation had elapsed the feed intake was not different between the two groups at W2 and W3. Initial body weight (at W0) was similar across groups. At the end of the first week body weight was significantly lower in the propionate group. There was no significant difference between the two groups after W2 and W3. The body weights of the two groups were similar at the beginning of the fourth week (Table 4).

\section{Changes in fasting plasma variables}

Fasting venous plasma glucose concentrations were always lower in rats fed on the propionate diet than in the rats fed on the control diet with a significant difference only at week 2 (Table 3). It should be noticed that at week 3 there were fewer samples than for the other weeks. The corresponding plasma insulin concentrations tended to be lower in the propionate group but these differences were not statistically significant. Plasma FFA levels were not significantly different between the two groups with a tendency to be lower in the propionate diet. Alanine, lactate, $\beta$-hydroxybutyrate, glycerol among the rats fed on the two diets were similar at any time-point during the 3-week follow-up.

At the beginning of the 4th week, if all propionate-fed rats were considered a group ( $n$ 21) $v$. all control diet-fed rats ( $n$ 18; Table 4 ), the mean fasting arterial plasma glucose concentration of the propionate group was significantly lower than those of the control-diet group. But if we considered the three subgroups of the two diet groups there was a significant difference only for the subgroup receiving the $0.6 \mathrm{U}$ exogenous insulin $/ \mathrm{kg}$ per $\mathrm{h}$ infusion.

\section{Effect of insulin on hepatic glucose production and whole-body glucose utilization}

In the basal state when no insulin was infused, the endogenous glucose production was not significantly different for propionate-fed rats $v$. control rats: 0.084 (SEM 0.007) v. 0.082 (SEM 0.007$) \mathrm{mmol} / \mathrm{min}$ per $\mathrm{kg}$. At plasma insulin concentrations of approximately $500 \mathrm{mU} / 1$, endogenous hepatic production was decreased by $65 \%(0.031$ (SEM 0.012$) \mathrm{mmol} / \mathrm{min}$ per $\mathrm{kg}$ ) in the propionate group and by $48 \% \quad(0.044$ (SEM $0.021) \mathrm{mmol} / \mathrm{min}$ per $\mathrm{kg}$ ) in the control group, without any significant difference. At 


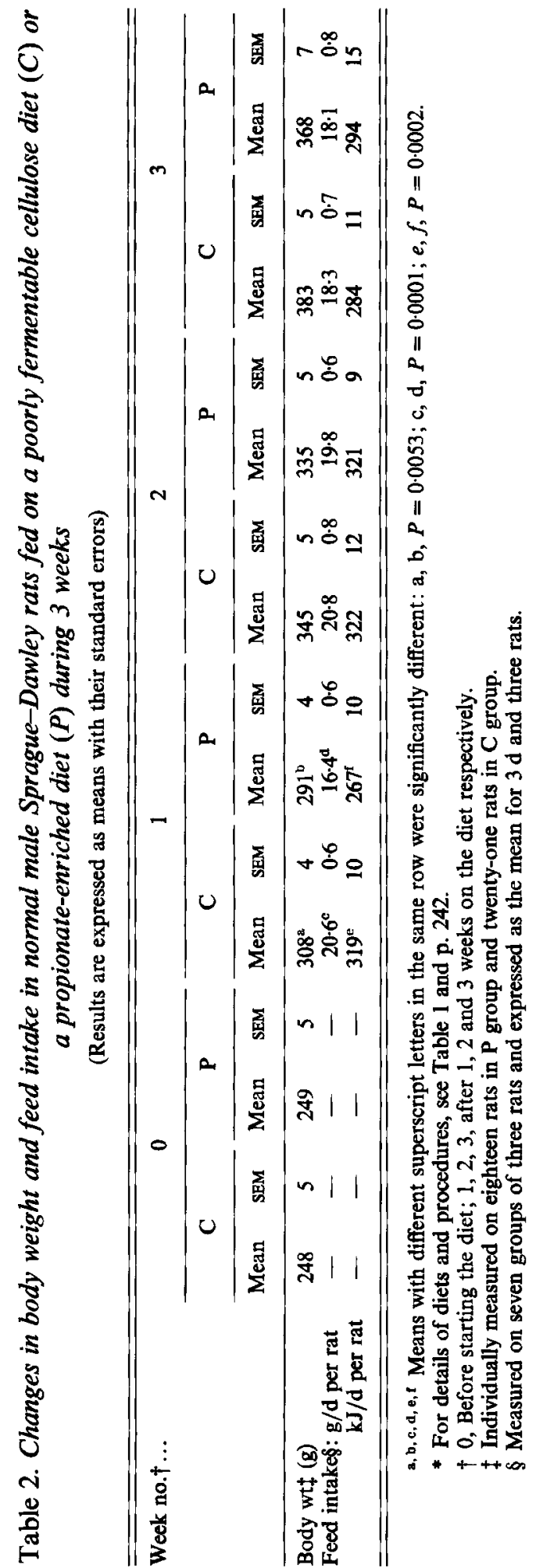




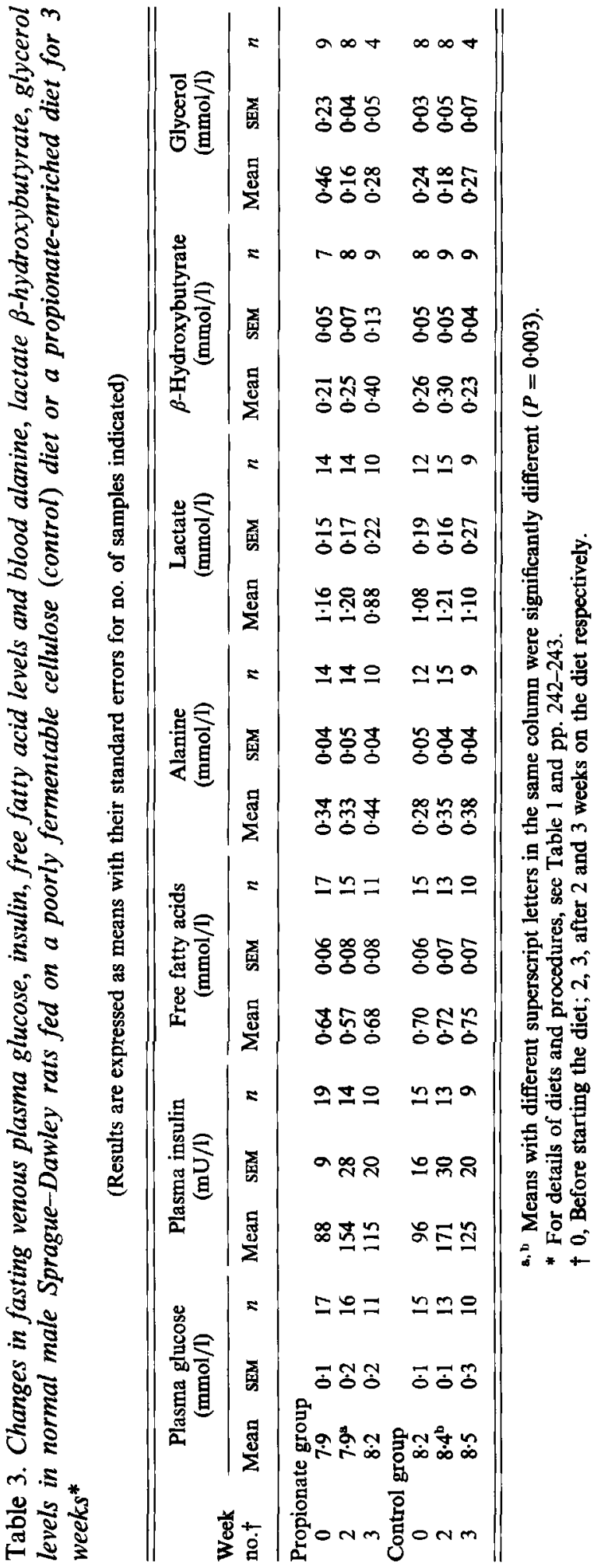


Table 4. Body weight ( $B W$ ), arterial plasma glucose and insulin, glucose and insulin infusion rates (IIR) during euglycaemic hyperinsulinaemic clamps at the beginning of the fourth week in rats fed on propionate-enriched and poorly fermentable cellulose (control) diets*

(Results are expressed as means with their standard errors for no. of animals indicated)

\begin{tabular}{|c|c|c|c|c|c|c|c|c|c|c|}
\hline & \multirow[b]{2}{*}{$n$} & \multirow[b]{2}{*}{ IIR $(\mathrm{U} / \mathbf{k g}$ per $\mathrm{h})$} & \multicolumn{2}{|c|}{ BW (g) } & \multicolumn{2}{|c|}{ SSPI (mU/l) } & \multicolumn{2}{|c|}{ BPG (mmol/l) } & \multicolumn{2}{|c|}{ SSPG $(\mathrm{mmol} / \mathrm{l})$} \\
\hline & & & Mean & SEM & Mean & SEM & Mean & SEM & Mean & SEM \\
\hline \multicolumn{11}{|c|}{ Propionate group } \\
\hline & 6 & 0 & 399 & 12 & 217 & 49 & 8.6 & 0.4 & $8 \cdot 5$ & 0.7 \\
\hline & 7 & 0.6 & 370 & 12 & 509 & 47 & $7 \cdot 4^{\mathrm{s}}$ & 0.2 & $7 \cdot 2^{c}$ & 0.2 \\
\hline & 8 & 2 & 385 & 7 & 1694 & 146 & $7 \cdot 7$ & 0.2 & $7 \cdot 6$ & 0.2 \\
\hline Total & 21 & & 384 & 6 & & & $7 \cdot 7^{e}$ & 0.2 & & \\
\hline \multicolumn{11}{|c|}{ Control group } \\
\hline & 7 & 0 & 401 & 8 & 217 & 47 & $9 \cdot 4$ & $0 \cdot 8$ & $8 \cdot 7$ & 0.2 \\
\hline & 5 & 0.6 & 379 & 20 & 497 & 62 & $8 \cdot 7^{\mathrm{b}}$ & 0.5 & $8 \cdot 6^{d}$ & 0.5 \\
\hline & 6 & 2 & 362 & 12 & 1528 & 93 & $8 \cdot 2$ & 0.2 & 7.9 & 0.3 \\
\hline Total & 18 & & 382 & 8 & & & $8 \cdot 5^{t}$ & $0 \cdot 2$ & & \\
\hline
\end{tabular}

$a, b, c, d, e, f$ Means with different superscript letters in the same column were significantly different: ${ }^{a, b} P=0.04$; c, d $P=0.03 ;{ }^{\text {e, }} P=0.0025$.

SSPI, steady-state plasma insulin; BPG, basal plasma glucose. SSPG, steady-state plasma glucose.

* For details of diets and procedures, see Table 1 and pp. 242--245.

Table 5. Glucose kinetics during euglycaemic hyperinsulinaemic clamps in rats fed on propionate-enriched and poorly fermentable cellulose (control) diet*

(Experiments were performed at the beginning of the fourth week feeding. Results are expressed as means with their standard errors for no. of animals indicated)

\begin{tabular}{|c|c|c|c|c|c|c|c|c|c|c|c|}
\hline & \multirow[b]{2}{*}{$n$} & \multicolumn{2}{|c|}{$\begin{array}{c}\text { SSPI } \\
(\mathrm{mU} / 1)\end{array}$} & \multicolumn{2}{|c|}{$\begin{array}{c}\text { SSGIR } \\
(\mathrm{mmol} / \mathrm{kg} \\
\text { per } \mathrm{min})\end{array}$} & \multicolumn{2}{|c|}{$\begin{array}{c}\text { GPR } \\
(\mathrm{mmol} / \mathrm{kg} \\
\text { per min) }\end{array}$} & \multicolumn{2}{|c|}{$\begin{array}{c}\text { GUR } \\
(\mathrm{mmol} / \mathrm{kg} \\
\text { per } \mathrm{min})\end{array}$} & \multicolumn{2}{|c|}{$\begin{array}{c}\text { GMC } \\
(\mathrm{ml} / \mathrm{kg} \\
\text { per min })\end{array}$} \\
\hline & & Mean & SEM & Mean & SEM & Mean & SEM & Mean & SEM & Mean & SEM \\
\hline Propionate group & $\begin{array}{l}6 \\
7 \\
8\end{array}$ & $\begin{array}{r}217 \\
509 \\
1694\end{array}$ & $\begin{array}{r}49 \\
47 \\
146\end{array}$ & $\begin{array}{l}-\overline{107} \\
0 \cdot 150\end{array}$ & $\begin{array}{l}-\overline{0 .} \\
0.009\end{array}$ & $\begin{array}{l}0.084 \\
0.031 \\
0.034\end{array}$ & $\begin{array}{l}0.007 \\
0.012 \\
0.015\end{array}$ & $\begin{array}{l}0 \cdot 084 \\
0 \cdot 130 \\
0 \cdot 162\end{array}$ & $\begin{array}{l}0.007 \\
0.014 \\
0.022\end{array}$ & $\begin{array}{r}9 \cdot 9 \\
18 \cdot 0 \\
21 \cdot 4\end{array}$ & $\begin{array}{l}1 \cdot 1 \\
1 \cdot 9 \\
3 \cdot 1\end{array}$ \\
\hline Control group & $\begin{array}{l}7 \\
5 \\
6\end{array}$ & $\begin{array}{r}217 \\
497 \\
1528\end{array}$ & $\begin{array}{l}47 \\
62 \\
93\end{array}$ & $\begin{array}{l}-\overline{129} \\
0 \cdot 160\end{array}$ & $\begin{array}{l}-\overline{0.017} \\
0.014\end{array}$ & $\begin{array}{l}0.082 \\
0.043 \\
0.014\end{array}$ & $\begin{array}{l}0.007 \\
0.020 \\
0.006\end{array}$ & $\begin{array}{l}0.082 \\
0 \cdot 172 \\
0.167\end{array}$ & $\begin{array}{l}0.007 \\
0.029 \\
0.014\end{array}$ & $\begin{array}{r}8 \cdot 9 \\
19 \cdot 6 \\
21 \cdot 2\end{array}$ & $\begin{array}{l}0.8 \\
2.6 \\
1.8\end{array}$ \\
\hline
\end{tabular}

SSPI, steady-state plasma insulin; SSGIR, steady-state glucose infusion rate; GPR, endogenous glucose production rate: GUR, glucose utilization rate; GMC, glucose metabolic clearance.

* For details of diets and procedures, see Table 1 and pp. 242-245.

plasma insulin concentrations of approximately $1500 \mathrm{mU} / \mathrm{l}$, endogenous hepatic production was not completely suppressed in either group (0.034 (SEM 0.015) $\mathrm{mmol} / \mathrm{min} \mathrm{per} \mathrm{kg}$ in the propionate-fed group and 0.014 (SEM 0.006) $\mathrm{mmol} / \mathrm{min}$ per $\mathrm{kg}$ in the control group) without any significant difference. (Table 5).

Following submaximal insulin infusion or a very high plasma insulin level, the wholebody GUR was increased in both groups without any significant difference. Because propionate-fed and control rats were clamped at slightly different plasma glucose levels and 
because glucose utilization depends on glycaemia (Verdonk et al. 1981), we expressed the results in terms of glucose metabolic clearance (GMC; $\mathrm{ml} / \mathrm{min}$ per $\mathrm{kg}$ ). GMC was not significantly different between the two groups of animals.

\section{DISCUSSION}

The addition of propionate to the diet made a difference to the acceptability of the diet only during the first week of feeding. After this adaptation period there was no significant difference in feed intake. Weight change showed the same pattern, i.e. a significantly smaller weight decrease in the propionate-fed group at W1 which tended to disappear with time so that the two groups had a similar weight at the beginning of the 4th week.

The present study indicates that a small amount of propionate in the diet was associated with a lower fasting plasma glucose concentration. This was not associated with a lower feed intake or body weight. These results are in accordance with those observed in healthy subjects receiving sodium propionate-supplemented bread (Todesco et al. 1991) or with propionate capsules (Venter et al. 1990a). Both studies reported a lower fasting blood glucose level. However, in a study on Sprague-Dawley rats (Chen et al. 1984) it has been reported that fasting plasma glucose was not affected by propionate supplementation; it should be noted that the amount of propionate used in this study was very small $(3 \mathrm{~g} / \mathrm{kg})$. The dose used in our study was twenty times higher but, nevertheless, corresponded to the production of SCFA produced by total fermentation of a standard rat diet.

In our study there was no difference in plasma FFA between the two groups. A study in baboons (Venter $e t a l .1990 b$ ) reported that propionate induced a decrease in FFA levels after 4 weeks on the diet; no effect on fasting blood glucose was observed.

In our study the hepatic production measured by the isotopic method was expected to be lower in the propionate-fed group; this was not the case as there was no difference between the two groups. The study of whole-body insulin sensitivity (measured by clamp method) was unable to show a difference between the two groups. Venter et al. (1990a) and Todesco et al. (1991) have reported an improvement in carbohydrate tolerance measured by an oral glucose-tolerance test: the mean area under the glucose-tolerance curve and the corresponding mean area under the insulin-response curve were decreased in the propionate-supplemented group. However, the study of Venter et al. (1990a) did not provide evidence that insulin sensitivity was improved by propionate: indeed, lower FFA levels observed in the experimental group could be responsible for the apparent increase in insulin sensitivity. High circulating FFA levels are known to be associated with insulin insensitivity and inhibition of glucose uptake by muscle (Randle et al. 1963). In our study lower fasting plasma glucose levels were not associated with significantly lower circulating FFA. However, it should be noted that the fasting FFA levels had a tendency to be lower in the propionate-fed group without any significant difference.

Thus, in our study we observed a lowering effect of propionate on fasting plasma glucose without any evident changes in glucose production or whole-body glucose utilization. Propionate has been demonstrated to have some hypoglycaemic effect under certain circumstances (Oberholzer et al. 1967). The mechanism by which it acts at the cellular level has been well studied. Chan \& Freedland (1972) clearly demonstrated on isolated rat hepatocytes that propionate decreases gluconeogenesis from lactate and pyruvate by inhibition of the pyruvate pathway. The site of interaction they proposed is at the pyruvate carboxylase (EC 6.5.1.1) reaction which is inhibited by metabolic products of propionate, methylmalonyl-CoA and succinyl-CoA, specific inhibitors of this enzyme (Blair et al. 1973). Furthermore, propionate stimulates rates of glycolysis in isolated rat hepatocytes (Anderson \& Bridges, 1984) even though it has been shown to be gluconeogenic in vitro (Chan \& 
Freedland, 1972). From their study in humans, Todesco et al. (1991) concluded that reduced postprandial glucose response when propionate is added to bread is due to decreased digestibility by inhibiting amylase $(E C 3.2 .1 .1)$ activity, the longer-term effects on carbohydrate metabolism could result from adaptation in the absorptive capacity of the small intestine. We are unable to suggest from our findings the mechanism by which fasting plasma glucose is reduced in rats fed on a diet containing $60 \mathrm{~g}$ propionic acid $/ \mathrm{kg}$ for 3 weeks. Further studies are required to delineate the mechanism of action of propionate on glucose metabolism.

\section{REFERENCES}

Anderson, J. W. (1986). Dietary fiber and diabetes. In Dietary Fiber: Basic and Clinical Aspects, pp. 151-167 [G. V. Vahouny and D. Kritchevsky, editors]. New York: Plenum Press.

Anderson, J. W. \& Bridges, S. R. (1984). Short chain fatty acid fermentation products of plant fiber affect glucose metabolism of isolated rat hepatocytes (41958). Proceedings of the Society for Experimental Biology and Medicine 177, 372-376.

Anderson, J. W. \& Chen, W. L. (1979). Plant fiber: carbohydrate and lipid metabolism. American Journal of clinical Nutrition 32, 346-363.

Bär, A. (1990). Factorial calculation model for the estimation of the physiological caloric value of polyols. In Caloric Evaluation of Carbohydrates, pp. 209-257 [N. Hosoya, editor]. Tokyo: Japan Association of Dietetics and Enriched Foods.

Blair, J. B., Cook, D. E. \& Lardy, H. A. (1973). Interaction of propionate and lactate in the perfused rat liver. Journal of Biological Chemistry 248, 3608-3614.

Bornet, F. (1987). Effets des fibres alimentaires sur la digestion et le métabolisme des glucides (Effects of dietary fibres on carbohydrate metabolism and digestion). In Les Fibres Alimentaires, pp. 1-39 [J. F. Thibault and X. Rouau, editors]. Paris: Apria.

Chan, T. M. \& Freedland, R. A. (1972). The effect of propionate on the metabolism of pyruvate and lactate in the perfused rat liver. Biochemical Journal 127, 539-543.

Chen, W. J. L. \& Anderson, J. W. (1986). Hypocholesterolemic effects of soluble fibres. In Dietary Fiber: Basic and Clinical Aspects, pp. 275-286 [G. V. Vahouny and D. Kritchevsky, editors]. New York: Plenum Press.

Chen, W. L., Anderson, J. W. \& Jennings, D. (1984). Propionate may mediate the hypocholesterolemic effects of certain soluble plant fibers in cholesterol-fed rats. Proceedings of the Society for Experimental Biology and Medicine 175, 215-218.

Cummings, J. H. (1983). Fermentation in the human large intestine: evidence and implication for health. Lancet i, $161-166$.

Cummings, J. H., Pomare, E. W., Branch, W. J., Naylor, C. P. E. \& Macfarlane, G. T. (1987). Short chain fatty acids in human large intestine, portal, hepatic and venous blood. Gut 28, 1221-1227.

Gutmann, I. \& Wahlefeld, A. W. (1974). L(+)lactate determination with lactate dehydrogenase and NAD. In Methods of Enzymatic Analysis, pp. 1464-1468 [H. U. Bergmeyer, editor]. New York: Academic Press.

Jenkins, D. J. A., Wolever, T. M. S., Nineham, R., Sarson, D. L., Bloom, S. R., Ahern, J., Alberti, K. G. M. M. \& Hockaday, T. D. (1980). Improved glucose tolerance four hours after taking guar with glucose. Diabetologia 19, 21-24.

Katz, J., Rostami, H. \& Dunn, A. (1974). Evaluation of glucose turnover, body mass and recycling with reversible and irreversible tracers. Biochemical Journal 142, 161-170.

Keys, J. A., Van Soest, P. J. \& Young, E. P. (1969). Comparative digestibility of forage cellulose and hemicellulose in ruminants and non ruminants. Journal of Animal Science 29, 11-15.

Leturque, A., Burnol, A. F., Ferré, P. \& Girard, J. (1984). Pregnancy induced insulin resistance in rat: impaired suppression of glucose production and impaired stimulation of glucose utilization. American Journal of Physiology 246, E25-31.

Leturque, A., Gilbert, M. \& Girard, J. (1981). Glucose turnover during pregnancy in anaesthetized postabsorptive rats. Biochemical Journal 196, 633-636.

Livesey, G. \& Elia, M. (1988). Estimation of energy expenditure, net carbohydrate utilization, and net fat oxidation and synthesis by indirect calorimetry: evaluation of errors with special reference to the detailed composition of fuels. American Journal of Clinical Nutrition 47, 608-628.

McNeil, N. I., Cummings, J. H. \& James, W. P. T. (1978). Short chain fatty acid absorption by the human large intestine. Gut 19, 819-822.

Nyman, M., Asp, N. G., Cummings, J. H. \& Wiggens, H. (1986). Fermentation of dietary fibre in the intestinal tract: comparison between man and rat. British Journal of Nutrition 55, 487-496.

Oberholzer, V. G., Levin, B., Burgess, E. A. \& Young, W. F. (1967). Methylmalonic aciduria. An inborn error of metabolism leading to chronic metabolic acidosis. Archives of Disease in Childhood 42, 492-504.

Pénicaud, L., Kandé, J., LeMagnen, J. \& Girard, J. (1985). Insulin action during fasting and refeeding in rat determined by euglycaemic clamp. American Journal of Physiology 249, E514-518. 
Randle, P. J., Garland, P. B., Hales, C. N. \& Newsholme, E. A. (1963). The glucose-fatty acid cycle: Its role in insulin sensitivity and the metabolic disturbances of diabetes mellitus. Lancet $\mathbf{~}, 785-789$.

Ruppin, H., Bar-Meir, S., Soergel, K. H., Wood, C. M. \& Schmitt, M. G. (1980). Absorption of short chain fatty acids by the colon. Gastroenterology 78, 1500-1507.

Skutches, C. L., Holroyde, C. P., Myers, R. N., Paul, P. \& Reichard, G. A. (1979). Plasma acetate turnover and oxidation. Journal of Clinical Investigation 64, 708-713.

Somogyi, M. J: (1945). Determination of blood sugar. Journal of Biological Chemistry 160, 69-73.

Steele, R. (1959). Influence of glucose loading and of injected insulin on hepatic glucose output. Annals of the New York Academy of Sciences 82, 420-430.

Todesco, T., Venketshwer Rao, A., Bosello, O. \& Jenkins, D. J. A. (1991). Propionate lowers blood glucose and alters lipid metabolism in healthy subjects. American Journal of Clinical Nutrition 54, 860-865.

Venter, C. S. \& Vorster, H. H. (1989). Possible metabolic consequences of fermentation in the colon for humans. Medical Hypotheses 29, 161-166.

Venter, C. S., Vorster, H. H. \& Cummings, J. H. (1990a). Effects of dietary propionate on carbohydrate and lipid metabolism in healthy volunteers. American Journal of Gastroenterology 85, 549-553.

Venter, C. S., Vorster, H. H. \& Van Der Nest, D. G. (1990b). Comparison between physiological effects of konjac-glucomannan and propionate in baboons fed 'western' diets. Journal of Nutrition 120, 1046-1053.

Verdonk, C. A., rizza, R. A. \& Gerich, J. E. (1981). Effects of plasma glucose concentration on glucose utilization and clearance in normal man. Diabetes 30, 535-537.

Vorster, H. H., Venter, C. S., Van Eeden, T. S., Silvis, N., Huisman, H. W., Van Ryssen, J. C. J. \& Walker, A. R. P. (1988). Benefits from supplementation of the current recommended diabetic diet with gel fibre. International Clinical Nutrition Review 8, 140-146.

Wieland, O. (1974). Glycerol, UV method. In Methods of Enzymatic Analysis, pp. 1404-1408 [H. U. Bergmeyer, editor]. New York: Academic Press.

Wolever, T. M. S., Brighenti, F., Royall, D., Jenkins, A. L. \& Jenkins, D. J. A. (1989). Effect of rectal infusion of short chain fatty acids in human subjects. American Journal of Gastroenterology 84, 1027-1033.

Williamson, D. H. (1974). L-Alanine determination with alanine dehydrogenase. In Methods of Enzymatic Analysis, pp. 1679-1682 [H. U. Bergmeyer, editor]. New York: Academic Press.

Williamson, D. H. \& Mellanby, J. (1974). D(-)(3)-Hydroxybutyrate. In Methods of Enzymatic Analysis, pp. 1836-1839 [H. U. Bergmeyer, editor]. New York: Academic Press. 